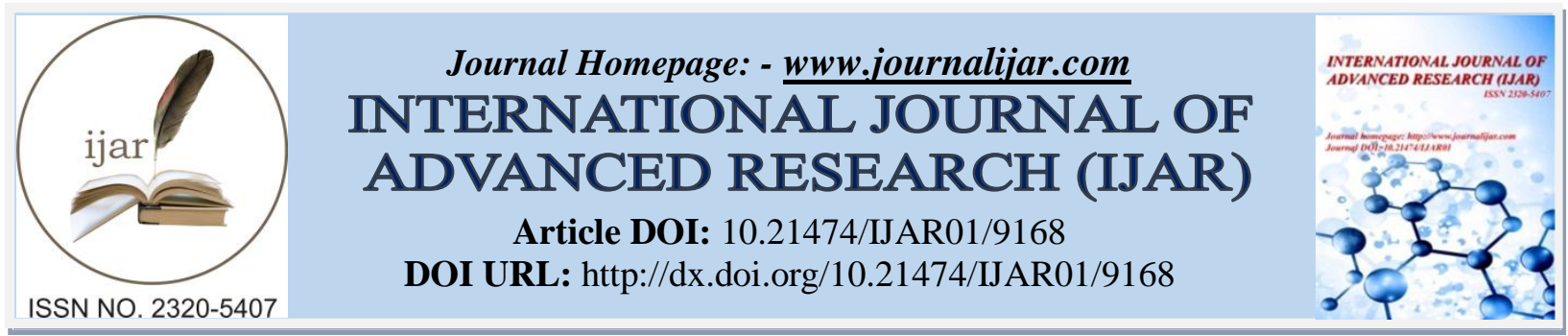

RESEARCH ARTICLE

\title{
COMPLETE DENTURE IMPRESSION MATERIALS AND TECHNIQUES PRACTICED BY PRIVATE DENTAL PRACTITIONERS: A SURVEY.
}

\section{Dr. Mansi Gupta ${ }^{1}$, Dr. Suprabha Rather ${ }^{2}$ And Dr. Geeta Paul ${ }^{3}$.}

1. Senior Lecturer, Department of Prosthodontics, Indraprastha dental College and hospital, sahibabad, Uttar Pradesh, India.

2. Reader, Department of Prosthodontics, Suprabha-SR ip Dental College.

3. Professor, Department of Prosthodontics, Suprabha-SR ip Dental College.

\section{Manuscript Info}

Manuscript History

Received: 24 March 2019

Final Accepted: 26 April 2019

Published: May 2019

Key words:-

Denture impression materials, dental

practitioners, a survey.

\section{Abstract}

A survey was done to find out what methods and materials dentists generally use for making impressions in complete dentures. It was seen that dentists generally resort to easier methods and materials that are relatively easy to use and less expensive.

\section{Introduction:-}

Impression making in complete denture is one of the important and crucial step which determines the success of complete denture fabrication. A good impression which includes all the land marks of edentulous mouth helps in good retention, support and stability of the complete denture.

There are several factors that contribute in successful impression making such as technique used, type of the material, and patient situation. Different techniques for making complete denture impression are given in text books and literature, showing diversity of options. Selection of the proper technique depends on the clinical situation, materials availability, clinician knowledge and experience [1].

A survey was carried out to check which materials and techniques are used by private practitioners to make impressions for complete dentures and what techniques are being followed.

\section{Materials and methods:-}

A questionnaire was prepared and sent to 200 dental practitioners. Only 170 responded. The practitioners were in the age group of 30-70 years. The dental surgeons were from Delhi-NCR. The questionnaire had six questions.

1. Which impression material do you use to make primary impression?

a. Impression compound

b. Alginate

c. Any other (please specify)

2. Which impression tray do you use for making primary impressions?

a. Stock tray with rim lock

b. Stock tray without rim lock

\section{Corresponding Author:-Mansi Gupta.}

Address:-Senior Lecturer, Department of Prosthodontics, Indraprastha dental College and hospital, sahibabad, Uttar Pradesh, India. 
3. What material do you use to construct custom tray?

a. Auto polymerizing resin

b. Shellac base plate

c. Any other (please specify)

4. What type of spacer do you use:

a. Full spacer

b. T-spacer

c. None

5. What material do you use for border molding?

a. Low fusing impression compound

b. Heavy body elastomeric impression material

6. What material do you use for secondary impression?

a. Zinc oxide eugenol impression material

b. Light body elastomeric impression material

c. Medium body elastomeric impression material

7. Do you disinfect the impressions made?

a. Yes

b. No

8. What disinfection material do you use?

a. Alcohol

b. Bleach

c. Glutraldehyde

d. Rinse with tap water

\section{Results:-}

It was observed that $74 \%$ of practitioners use stock tray with rim lock and rest $26 \%$ without rim lock.

Alginate was most commonly used impression material amounting to $73 \%$ and rest used impression compound. No other material was used.

Practitioners mostly got their custom tray for secondary impression made in auto polymerizing resin. Only $8 \%$ used shellac base plate for construction of custom tray.

Practitioners generally didn't use spacer on the custom tray. Only 23\% used full spacer and $12 \%$ used T-Spacer.

Low fusing impression compound was used by $75 \%$ of the practitioners and $25 \%$ used elastomeric impression material.

Again zinc oxide eugenol impression paste was used by $77 \%$ of practitioners. $18 \%$ used light body elastomeric impression material and 5\% used medium body elastomeric impression material for both border molding and secondary impression.

Only $14 \%$ disinfected the impressions. Glutaraldehyde was the choice for disinfecting the impression. $86 \%$ only rinsed with water.

\section{Discussion:-}

Impression making is an integral part of getting a good prosthesis. The survey was assessed and it was seen that mostly easier techniques were used by practitioners. 
It was seen that only $74 \%$ of the practitioners used rim lock trays for making primary impressions. Most of the practitioners used alginate impression material for making the primary impression. The most recognized primary impression materials are alginate and impression compound [2, 3]. Rim lock trays provide added retention for the material.

After preparing the primary cast a custom tray is fabricated. It is imperative that the tray is rigid and dimensionally stable. Tray prepared from thermoplastic material can lead to inaccurate impressions [4]. Cold cure acrylic resin can be used to prepare custom trays [5]. Mostly practitioners used cold cure acrylic resin for making secondary tray.

Border molding is carried out with low fusing compound i.e. green stick [5] or putty/heavy body elastomer [6]. Practitioners in this survey mostly used green stick for the border molding.

Secondary or final impression is recorded with a wash material like ZOE paste or non-eugenol impression paste. Light body elastomer can also be used $[5,7,8]$. Alginate should not be used as it is a bulk impression material. The recommended thickness is about $3 \mathrm{~mm}$. In a wash, with thickness of about $1 \mathrm{~mm}$ dimensional changes may be high and ability to record details is questionable. Most commonly used was ZOE paste by practitioners. In North American dental schools, polysulfide was used by $48 \%$ and polyether by $4 \%$ to record final impressions [9]. In a survey of practitioners in UK the findings were almost same [10]. In another study of US prosthodontists and dental schools it was noted that $36 \%$ prosthodontists and $64 \%$ schools used elastomers for making final impressions [11].

Disinfection was not generally used and most practitioners just rinsed with water.

\section{Conclusion:-}

This study was done to check the trend that flowed amongst dentists for making impressions in complete dentures. It was seen that dentists generally use easier methods and materials that are less expensive and easier to use.

\section{References:-}

1. Alqattan et al. Impression Techniques and Materials for Complete Denture Construction. Dent Health Curr Res. 2016; 2:1.

2. Basker RMDJ, Tomlin HR. Prosthetic treatment of the edentulous patient, 3rd edtn. Macmillan Press, London, 1976.

3. Fenn HRB, MacGregor AR. Fenn, Liddelow, and Gimsons' clinical dental prosthetics. 3rd edtn. London, 1989.

4. Vinay R. Complete denture Impression Techniques Practised by Private Dental Practitioners: A Survey. J Indian Prosthodont Soc. 2013; 13(3):233-235.

5. Anusavice KJ. Phillip's science of dental materials, 11th edn. Anusavice. 2006; 752:243-250.

6. Felton D. Complete dentures: DCNA, WB Saunders Company. 1996; 40(1):39-51.

7. O'Brien WJ. Dental materials and their selection, 3rd edn. Quintessence Books, Chicago. 2002; 9:92-96.

8. Von Noart R. Introduction to dental materials, 3rd edn. Mosby, New York, 2007, 188-192.

9. Arbree NS, Fleck S, Askinas SW. The results of a brief survey of complete denture prosthodontic techniques in pre doctoral programs in North American dental schools. J Prosthodont. 1996; 5(3):211-225.

10. Hyde TP, McCord JF. Survey of prosthodontic impression procedures for complete dentures in general dental practice in UK. J Prosthet Dent. 1999; 81(3):295-299.

11. Petrie CS, Walker MP, Williams K. A survey of US prosthodontists and dental Schools on the current materials and methods for final impression for complete denture prosthodontics. J Prosthodont. 2005; 14(4):253-262. 